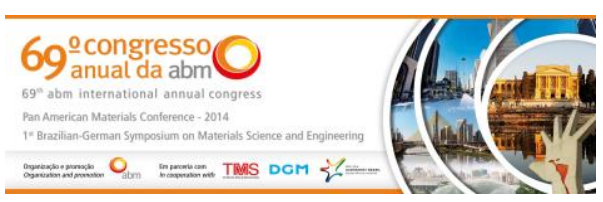

Tema: Tratamento Térmico

\title{
INFLUÊNCIA DO CROMO NAS PROPRIEDADES MECÂNICAS E METALÚRGICAS DO AÇO SAE1040*
}

\author{
Marcos Vinícios de Souza ${ }^{1}$ \\ Thalles Vinícios Morais Caldeira² \\ Larissa de Barros Machado Vilela ${ }^{2}$ \\ Roney Eduardo Lino ${ }^{3}$ \\ Leandro Aparecido Marchi ${ }^{3}$ \\ João Bosco dos Santos ${ }^{4}$ \\ Ricardo Luiz Perez Teixeira ${ }^{5}$
}

Resumo

Os aços carbono são materiais metálicos muito importantes na fabricação de peças para a indústria metal-mecânica. Parafusos, hastes, eixos, pistões, engrenagens são fabricados a partir desse tipo de aço, mais especificamente do aço SAE1040. O objetivo desse trabalho foi de avaliar a influência da presença de $0,2 \%$ em massa de cromo nas propriedades mecânicas e metalúrgicas de um aço com $0,4 \%$ em massa de carbono. A liga padrão SAE1040 e esta liga modificada com cromo foram submetidas a tratamentos térmicos de normalização, recozimento, têmpera e revenimento, e comparadas às durezas e microdurezas das diferentes amostras entre si. Os resultados obtidos evidenciaram que a adição de cromo é um método eficiente quando se deseja aumentar a resistência de um material. Observou-se que os valores de dureza e microdureza para o aço com a adição de cromo apresentaram-se maiores em relação ao aço padrão, como consequência das microestruturas obtidas, principalmente após têmpera e revenimento. A adição de $0,2 \%$ em massa de cromo no aço carbono influiu na melhora das propriedades mecânicas do aço tornando-o mais interessante na fabricação de peças para a indústria metal-mecânica.

Palavras-chave: Cromo; Tratamento térmico; SAE1040; Ensaios mecânicos; Aço.

\section{INFLUENCE OF CHROMIUM MECHANICAL AND METALLURGICAL PROPERTIES} OF STEEL SAE 1040

\section{Abstract}

Carbon steels are very important materials in parts production to the metal-mechanical industry. Screws, rods, shafts, pistons, gears are manufactured to this kind of steel, more specifically SAE1040 steel. The objective of this study was to evaluate the influence of the presence of $0.2 \mathrm{wt} \%$ of chromium in the mechanical and metallurgical properties of steel with $0.4 \mathrm{wt} \%$ carbon. The standard alloy SAE1040 and this alloy modified by chromium were submitted to heat treatment of normalization, annealing, quenching and tempering, and was compared to the hardness and microhardness of different samples to each other. The results showed that the addition of chromium is an efficient method when you want to increase the resistance a material. It was observed that the values for hardness and microhardness for the steel with the addition of chromium were bigger in relation to standard steel, it because of the microstructures obtained after quenching and tempering. The addition of $0.2 \mathrm{wt} \%$ of chromium in carbon steel influenced the improvement of mechanical properties of steel, making it more interesting for the manufacture of parts for the metalworking industry. Keywords: Chromium, Heat treatment; Standard alloy; SAE1040; Mechanical tests; Steel.

1 Aluno de Graduação em Engenharia Metalúrgica, Departamento de Engenharia Metalúrgica e de Materiais, Faculdade de Engenharia (FaEnge), Universidade do Estado de Minas Gerais (UEMG), João Monlevade, MG, Brasil.

2 Aluno(a) de Graduação em Engenharia Metalúrgica, Departamento de Engenharia Metalúrgica e de Materiais, FaEnge, UEMG, João Monlevade, MG, Brasil.

3 Mestre, Professor, Departamento de Engenharia Metalúrgica e de Materiais, FaEnge, UEMG, Eng. Metalurgista, ArcelorMittal Monlevade, João Monlevade, MG, Brasil.

4 Mestre, Professor, Departamento de Engenharia Metalúrgica e de Materiais, FaEnge, UEMG, João Monlevade, MG, Brasil.

5 Doutor em Engenharia Metalúrgica e de materiais pela UFRJ, Professor de Materiais Metálicos pela Universidade Federal de Itajubá, Campus Avançado de Itabira, Itabira, MG, Brasil.

* Contribuição técnica ao 69 Congresso Anual da ABM - Internacional e ao 14ํㅡㄹ ENEMET - Encontro Nacional de Estudantes de Engenharia Metalúrgica, de Materiais e de Minas, 21 a 25 de julho de 2014, São Paulo, SP, Brasil. 


\section{INTRODUÇÃO}

Aço é um liga ferro-carbono contendo geralmente entre 0,008 até 2,11\% em massa de carbono. Essa liga, em função de sua composição química e processamento, tem uma ampla faixa de propriedades possíveis e isso com o custo competitivo a tornam aplicável à maioria dos equipamentos, móveis, veículos e a diversos setores da economia [1].

Os aços que têm estrutura de grãos predominantemente perlítica são amplamente usados na fabricação de trilhos, rodas, cordoalhas para pneus, barras de reforço, eixos e fio-máquina para trefilação. Já os aços médio carbono ligados, são usados principalmente após tratamento térmico de beneficiamento (têmpera e revenimento), cujo exemplo de aplicação típica é a fabricação de parafusos de alta resistência [2]. Os aços estudados neste trabalho, pertencente à família SAE/AISI 1040 temperável, são recomendados para fabricação de componentes para automóveis, como haste de amortecedor, alavanca de freio, barra de distribuição, biela, eixo e parafuso. A principal limitação destes materiais são a sua baixa dureza e propriedades baixas de resistência ao atrito. Por essa razão, têm sido feitas muitas tentativas para melhorar dureza e as propriedades tribológicas deste tipo de material [3].

Visto o potencial de aplicação desse tipo de aço, pretende-se com este trabalho oferecer uma contribuição ao desenvolvimento e à pesquisa de aços ao carbono estudando a influência do cromo nas propriedades mecânicas e metalúrgicas do aço AISI/SAE 1040 submetido a diversos tratamentos térmicos. As conclusões deste trabalho servirão de base para projeções futuras de tempos e temperaturas adequadas para obter-se um material com melhores propriedades.

Os elementos de ligas são adicionados ao aço com 0 intuito de produzir propriedades mecânicas e físicas necessárias para uma determinada aplicação. Nos aços, os elementos de liga formam uma solução sólida com o ferro, ou contribuem para a formação de carbonetos e carbonitretos, além de ser possível a formação de inclusões não metálicas e compostos intermetálicos [1].

A presença de cromo como um elemento de liga eleva a temperatura de início de formação de martensita, da resistência à corrosão, da dureza, resistência ao desgaste (se o \%C for alto), minimização da queda de dureza no revenido. Além disso, ele acelera o processo de esferoidização, pois, estabiliza a cementita na austenita que se forma durante o tratamento térmico em temperaturas acima de $A_{c 1}$, impedindo que a cementita se dissolva na matriz austenítica [4].

O cromo no aço é responsável pelo aumento da temperatura de transformação eutetóide e assim pelo refinamento da estrutura em aços stelmorizados de estrutura perlítica [5]. A adição de cromo no aço perlítico também acarreta uma diminuição no espaçamento interlamelar devido ao aumento na temperatura eutetóide [6].

Em um aço 1050 o cromo diminui o alongamento e aumenta limite de escoamento e resistência à tração, em média $27 \mathrm{MPa}$ [7].

Os diagramas TTT (tempo-temperatura-transformação) descrevem as microestruturas que se formam a partir da transformação austenítica à temperatura constante como uma função do tempo [8]. A Figura 1 mostra os diagramas TTT de dois diferentes tipos de aços, onde é possível prever o comportamento de um aço com a adição de cromo e outros elementos de liga. Observa-se ao comparar as curvas, que um acréscimo do teor de cromo leva ao deslocamento das curvas do diagrama TTT para à esquerda, diminuindo a taxa de resfriamento necessária para formar martensita, aumentado a temperabilidade do aço trabalhado.

* Contribuição técnica ao 69ํCongresso Anual da ABM - Internacional e ao 14 ENEMET - Encontro Nacional de Estudantes de Engenharia Metalúrgica, de Materiais e de Minas, 21 a 25 de julho de 2014, São Paulo, SP, Brasil. 

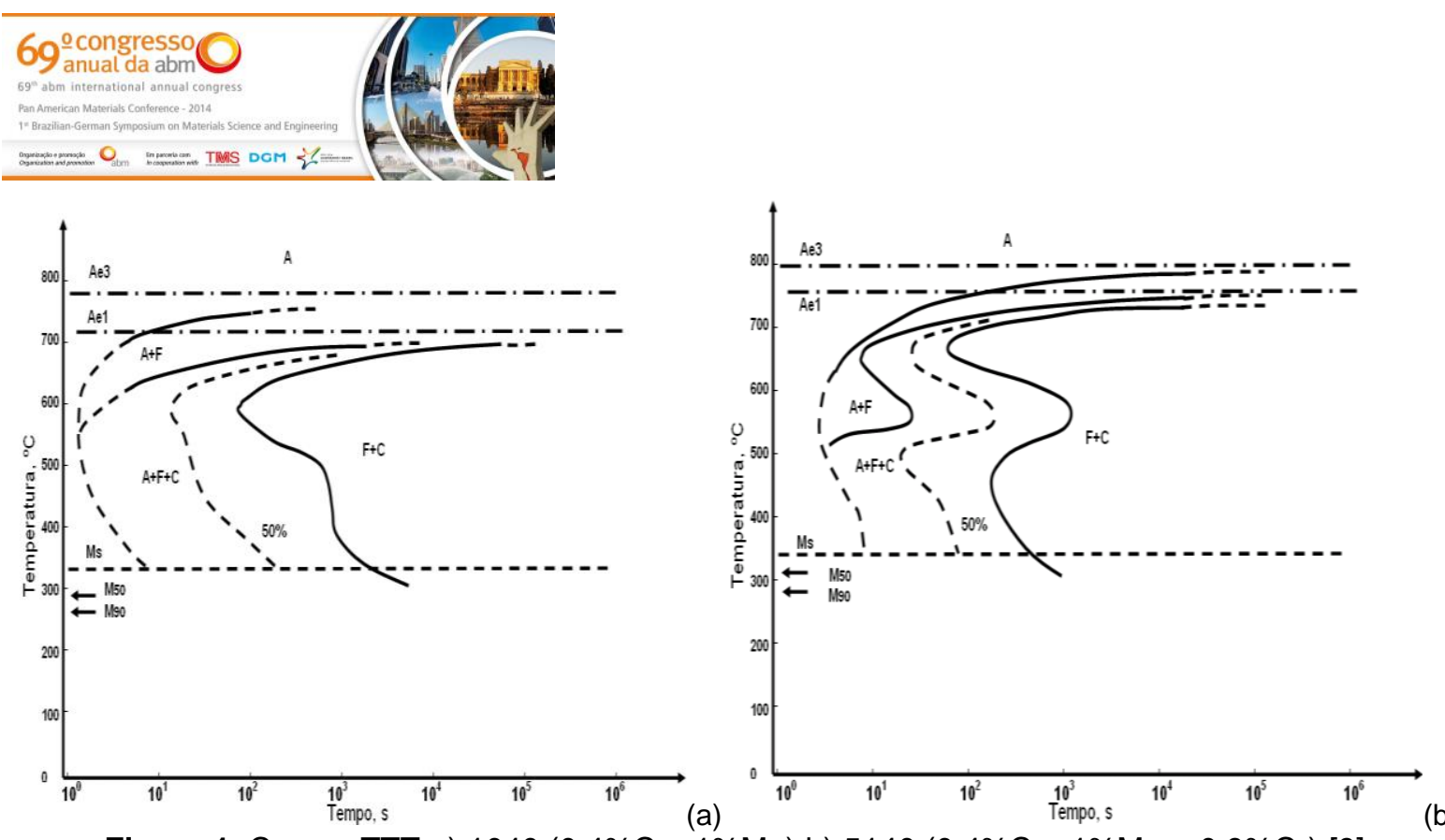

Figura 1. Curvas TTT a) $1040(0,4 \% \mathrm{C}+1 \% \mathrm{Mn})$ b) $5140(0,4 \% \mathrm{C}+1 \% \mathrm{Mn}+0,9 \% \mathrm{Cr})$ [9] .

Adições de elementos de liga incluindo o cromo causam mudanças acentuadas no diagrama de fases ferro-carbono. Analisando a Figura 2, nota-se um deslocamento da posição do ponto eutetóide para a esquerda para menores teores de carbono.

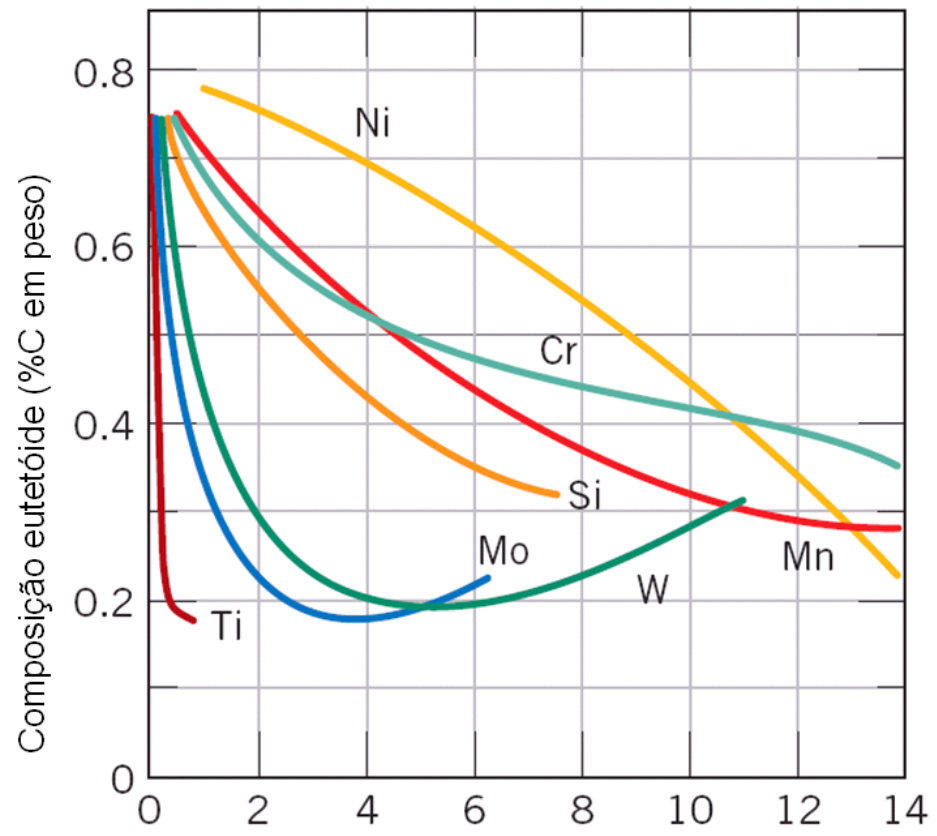

Concentração dos elementos de liga ( $\%$ em peso)

Figura 2. A dependência da temperatura eutetóide em função da concentração da liga para vários elementos de liga no aço [10].

\section{MATERIAIS E MÉTODOS}

Para a realização deste estudo utilizou-se dois aços de médio carbono, cujas composições químicas são indicadas na Tabela 1. Como pode ser observado, o que os diferenciam é o percentual de cromo, sendo que o Aço Padrão apresentou teor final deste elemento igual a 0,013\%, enquanto o Aço Padrão+Cr, 0,204\% em massa. Os aços foram fornecidos na forma de barra com diâmetro de 20,00 mm.

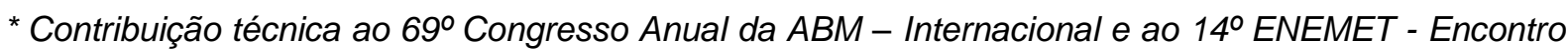
Nacional de Estudantes de Engenharia Metalúrgica, de Materiais e de Minas, 21 a 25 de julho de 2014, São Paulo, SP, Brasil. 


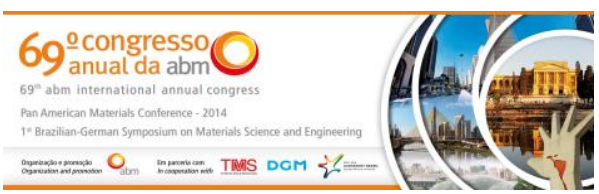

A análise do carbono foi realizada pelo processo de combustão e os demais elementos foram quantificados por espectrometria de emissividade óptica.

Tabela 1. Faixa de composição química especificada para os aços estudados (\% em peso) para o diâmetro considerado.

\begin{tabular}{llllllllll}
\hline & $\mathrm{C}$ & $\mathrm{Cr}$ & $\mathrm{Mn}$ & $\mathrm{Si}$ & $\mathrm{N}$ & $\mathrm{P}$ & $\mathrm{Al}$ & $\mathrm{Mo}$ & $\mathrm{S}$ \\
\hline Padrão & 0,44 & 0,013 & 0,624 & 0,299 & 0,0035 & 0,011 & 0,023 & 0,008 & 0,010 \\
Padrão+Cr & 0,44 & 0,204 & 0,707 & 0,262 & 0,0026 & 0,017 & 0,026 & 0,006 & 0,011 \\
\hline
\end{tabular}

Fonte: Laboratório químico - LECO.

Para os tratamentos térmicos foram retiradas amostras na forma cilíndrica com 10 $\mathrm{mm}$ de comprimento e do diâmetro do material como recebido. Abaixo, segue os tratamentos realizados.

\subsection{Têmpera e Revenimento}

Iniciou-se o experimento com todos os corpos de prova sendo austenitizados à temperatura de $835^{\circ} \mathrm{C}$ por 40 minutos no forno mufla. A temperatura de austenitização foi escolhida de acordo com simulações realizadas com o software Stecal 3.0. As amostras foram resfriados em óleo.

$\mathrm{O}$ revenimento foi aplicado por 30 minutos às temperaturas de $300^{\circ} \mathrm{C}, 500^{\circ} \mathrm{C}, 600^{\circ} \mathrm{C}$ e $700^{\circ} \mathrm{C}$.

Para estudo do tamanho de grão austenítico, outras amostras foram temperadas.

Normalização

As amostras dos dois tipos de aços foram aquecidas em forno tipo mufla em $835^{\circ} \mathrm{C}$. O tempo de permanência foi de 40 minutos, tempo necessário para ocorrer a austenitização da amostra. Após aquecimento, as amostras foram resfriadas ao ar, sendo colocadas sobre um tijolo refratário localizado ao lado da mufla.

\subsection{Recozimento}

Manteve as mesmas condições de austenitização do tratamento térmico de normalização: temperatura do forno em $835^{\circ} \mathrm{C}$ e tempo de encharque de 40 minutos. Seguido desse período, o forno foi desligado e as amostras permaneceram no seu interior, sendo apenas removidas quando atingiu a temperatura ambiente.

As amostras foram analisadas metalograficamente por microscopia ótica, nas seções transversais das mesmas. De cada tratamento térmico foram preparadas duas amostras metalográficas, um para Aço Padrão e outra para a Padrão+Cr.

Para revelação das estruturas obtidas nas condições de normalização, recozimento e revenimento as amostras foram atacadas com o reativo nital $2 \%$ durante 10 segundos. Enquanto, para revelar os contornos de grãos austeníticos, fez o uso de uma solução com $75 \mathrm{~mL}$ de $\mathrm{H}_{2} \mathrm{O}, 55 \mathrm{~mL}$ de teepol (detergente industrial) e 3 gramas de ácido pícrico durante 15 segundos. O tamanho de grão austenítico foi determinado através do método planimétrico (ASTM E112). Fez o uso do microscópio ótico da marca Aristomet.

Um esquema resumido dos tratamentos térmicos realizados pode ser visto na Figura 3.

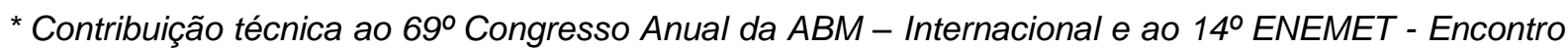
Nacional de Estudantes de Engenharia Metalúrgica, de Materiais e de Minas, 21 a 25 de julho de 2014, São Paulo, SP, Brasil. 

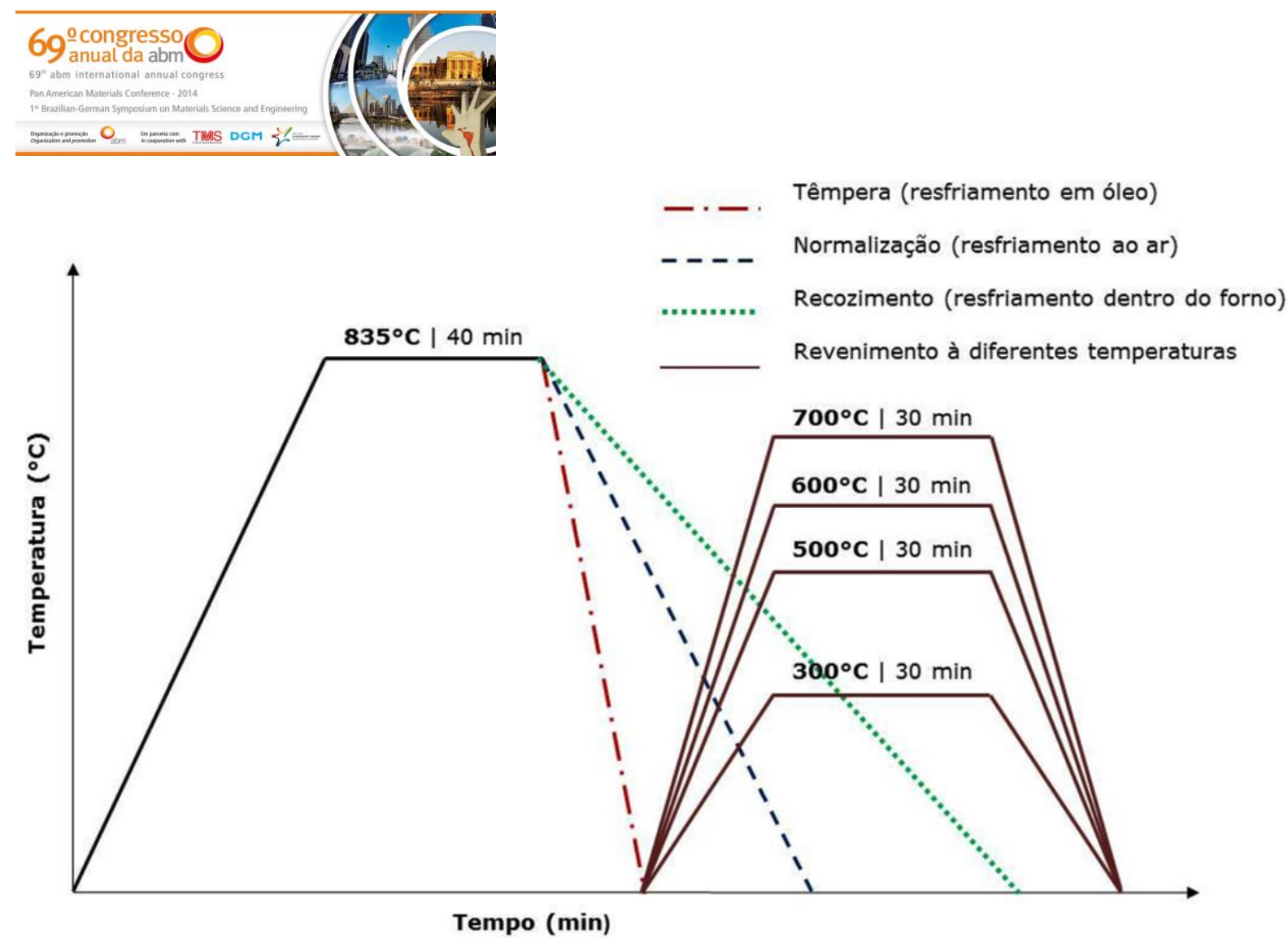

Figura 3. Representação esquemática de todos os tratamentos térmicos realizados. As amostras foram austenitizadas por 40 minutos na temperatura de $835^{\circ} \mathrm{C}$, seguidas de tratamento térmico de normalização, recozimento e têmpera. As amostras temperadas foram revenidas a temperaturas de $300,500,600$ e $700^{\circ} \mathrm{C}$, para um tempo de encharque de $30 \mathrm{~min}$.

Utilizou-se um durômetro para se medir a dureza das amostras tratadas termicamente. Foram conduzidos ensaios de dureza brinell em cada uma das amostras devidamente lixadas até a granulometria de 600 micrômetros. As medidas foram realizadas no durômetro da marca Wolpert, modelo HT1A.

As amostras da análise microestrutural foram avaliadas em relação à microdureza em regiões diferentes para que se pudesse evidenciar se houve variações de dureza relacionadas às variações microestruturais, não detectáveis em dureza macroscópica. Os ensaios de microdureza foram executados aplicando uma carga de $2.942 \mathrm{~N}$ por 12 segundos. Para tanto foi utilizado um microdurômetro digital fabricado pela o Struers modelo Duramin.

\section{RESULTADOS E DISCUSSÃO}

\subsection{Tamanho de Grão Austenítico}

A Tabela 2 exibe o tamanho de grão austenítico (TGA) dos aços Padrão e Padrão+Cr. A partir da observação da tabela pode se notar que as amostras alcançaram um resultado bem próximo, não se percebe diferença significativa em relação ao tamanho de grão da austenita prévia.

* Contribuição técnica ao 69 Congresso Anual da ABM - Internacional e ao 14ํㅡㄹ ENEMET - Encontro Nacional de Estudantes de Engenharia Metalúrgica, de Materiais e de Minas, 21 a 25 de julho de 2014, São Paulo, SP, Brasil. 


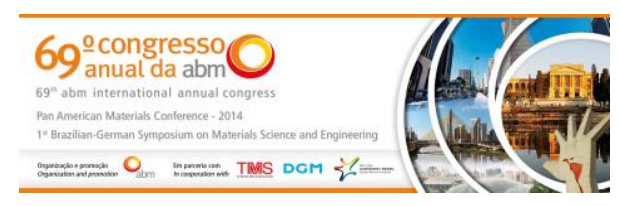

Tabela 2. Tamanho de grão austenítico ASTM para o aço Padrão e Padrão+Cr

\begin{tabular}{|c|c|}
\hline Aço & Tamanho de grão austenítico (ASTM) \\
\hline Padrão & $9,0 \pm 0,4$ \\
Padrão+Cr & $9,2 \pm 0,5$ \\
\hline
\end{tabular}

\subsection{Tratamentos Térmicos}

A estrutura do material na condição normalizada é apresentada na Figura 4. O ataque com Nital revelou a microestrutura dos aços Padrão e Padrão+Cr formada por ferrita pró-eutetóide em tons mais claros enquanto a perlita fina pode ser identificada em tonalidades mais escuras.

As amostras recozidas (Figura 4) apresentaram ferrita pró-eutetóide e perlita grosseira. Além disso, notam-se grandes grãos de ferrita e regiões de perlita. Percebe-se ao comparar as estruturas dos aços normalizados e recozidos que os aços normalizados apresentam estrutura mais refinada do que no estado recozido. Ao analisar a figura fica notável a diferença de estrutura dos aços temperados sem e com adição de cromo. Enquanto no aço Padrão verifica a existência de perlita fina, ferrita pró-eutetóide e martensita, no aço Padrão+Cr a presença de martensita é predominante. A martensita se encontra em grande quantidade devido à adição de cromo, que favorece a temperabilidade do aço estudado levando a maior quantidade dessa fase. Constata-se que a martensita está na forma de ripas.

Em relação ao revenimento observa uma mudança no aspecto de algumas microestruturas entre um aço com e sem adição de cromo para algumas diferentes temperaturas de revenimento (Figura 5). Para o revenimento a $300^{\circ} \mathrm{C}$, no aço Padrão+Cr a martensita oriunda da têmpera começa a ser rearranjada dando origem a martensita revenida enquanto, para o aço Padrão visualiza-se a presença de ferrita com agregados de carbonetos. Com a elevação da temperatura nota-se um refinamento da estrutura de ambos os aços, porém, no aço Padrão+Cr a intensidade é maior.

No aço com adição de cromo existe uma maior quantidade de carbonetos e os mesmos se encontram mais refinados e dispersos mais homogeneamente do que em relação ao aço Padrão (Figura 5). Nota-se que para revenimento ocorrido a $600^{\circ} \mathrm{C}$, no aço Padrão+ $\mathrm{Cr}$ uma quantidade relevante de carbonetos foi formada e 0 material se encontra parcialmente esferoidizado, enquanto, para o aço Padrão apenas a partir de $700^{\circ} \mathrm{C}$ podemos verificar-se o início dessa mudança de aspecto microestrutural.

* Contribuição técnica ao 69ํㅡㄴ Congresso Anual da ABM - Internacional e ao 14ำ ENEMET - Encontro Nacional de Estudantes de Engenharia Metalúrgica, de Materiais e de Minas, 21 a 25 de julho de 2014, São Paulo, SP, Brasil. 

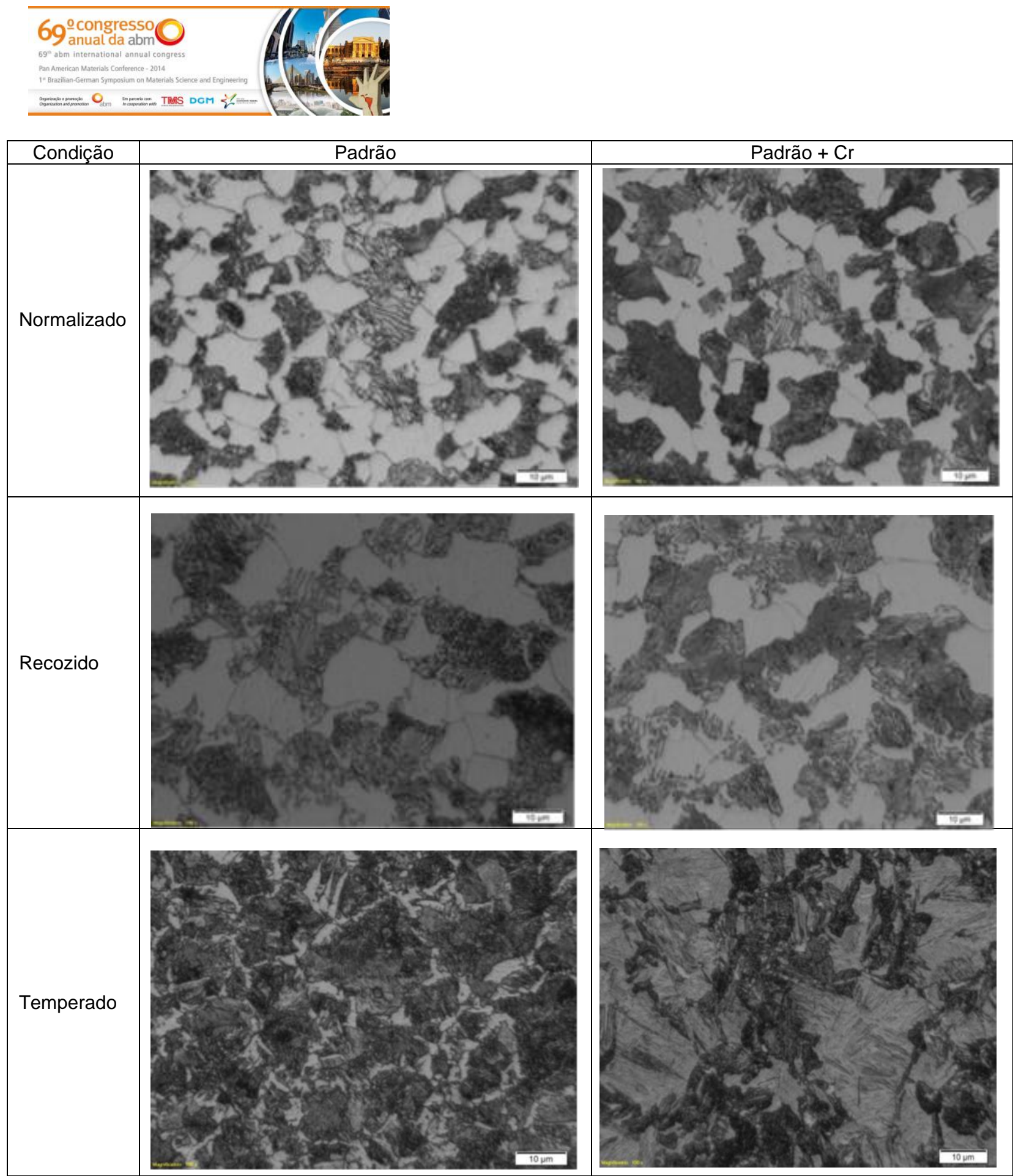

Figura 4. Micrografias dos aços Padrão e Padrão+Cr submetidos aos tratamentos térmicos de recozimento, normalização e têmpera.

* Contribuição técnica ao 69 Congresso Anual da ABM - Internacional e ao 14ํㅡㄹ ENEMET - Encontro Nacional de Estudantes de Engenharia Metalúrgica, de Materiais e de Minas, 21 a 25 de julho de 2014, São Paulo, SP, Brasil. 

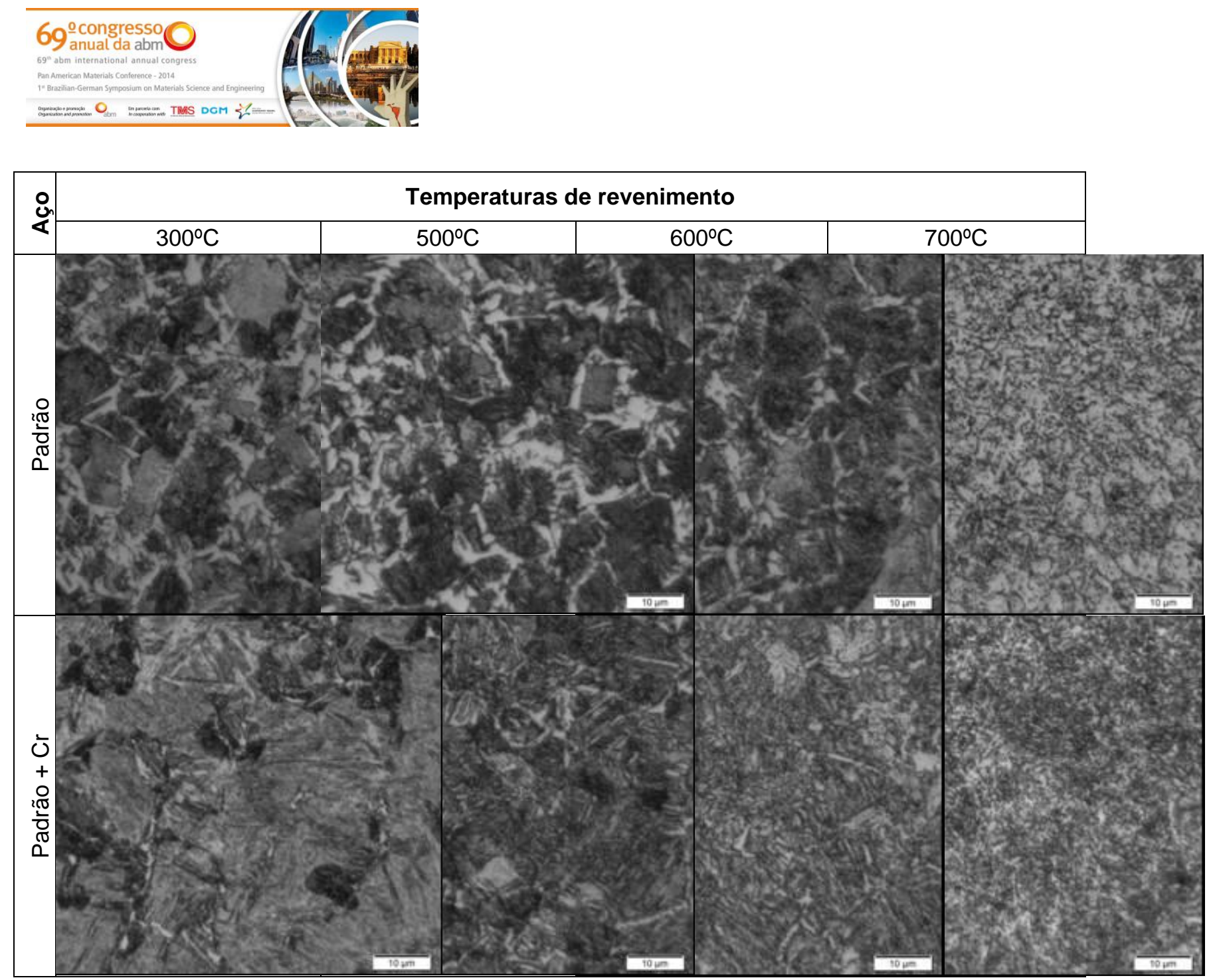

Figura 5. Evolução microestrutural dos aços Padrão e Padrão+Cr temperados e revenidos submetidos a diferentes temperaturas de revenimento. Ataque nital 2\%. 1000x. MO.

O aumento de temperatura de revenimento de 600 para $700 \stackrel{\circ}{C}$ para o aço Padrão provocou uma mudança na microestrutura bem significativa (Figura 5), enquanto para o aço Padrão+Cr, o efeito de crescimento de cementita foi minimizado. $\mathrm{O}$ cromo propicia uma maior taxa de nucleação de carbonetos e ocasiona uma menor taxa de crescimento com o tempo.

\subsection{Dureza}

Conforme figura 6, o aço Padrão+Cr apresentou, em geral, valores superiores de dureza na superfície em comparação ao aço Padrão nos tratamentos de recozimento e normalização. Isso se deve ao efeito do cromo no deslocamento do ponto eutetóide para à esquerda no diagrama binário ferro-carbono que provoca 0 aumento da formação de perlita sem acréscimo de mais carbono.

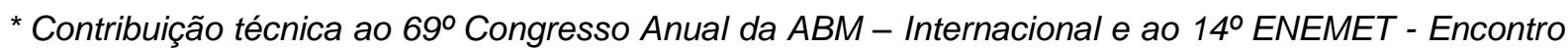
Nacional de Estudantes de Engenharia Metalúrgica, de Materiais e de Minas, 21 a 25 de julho de 2014, São Paulo, SP, Brasil. 

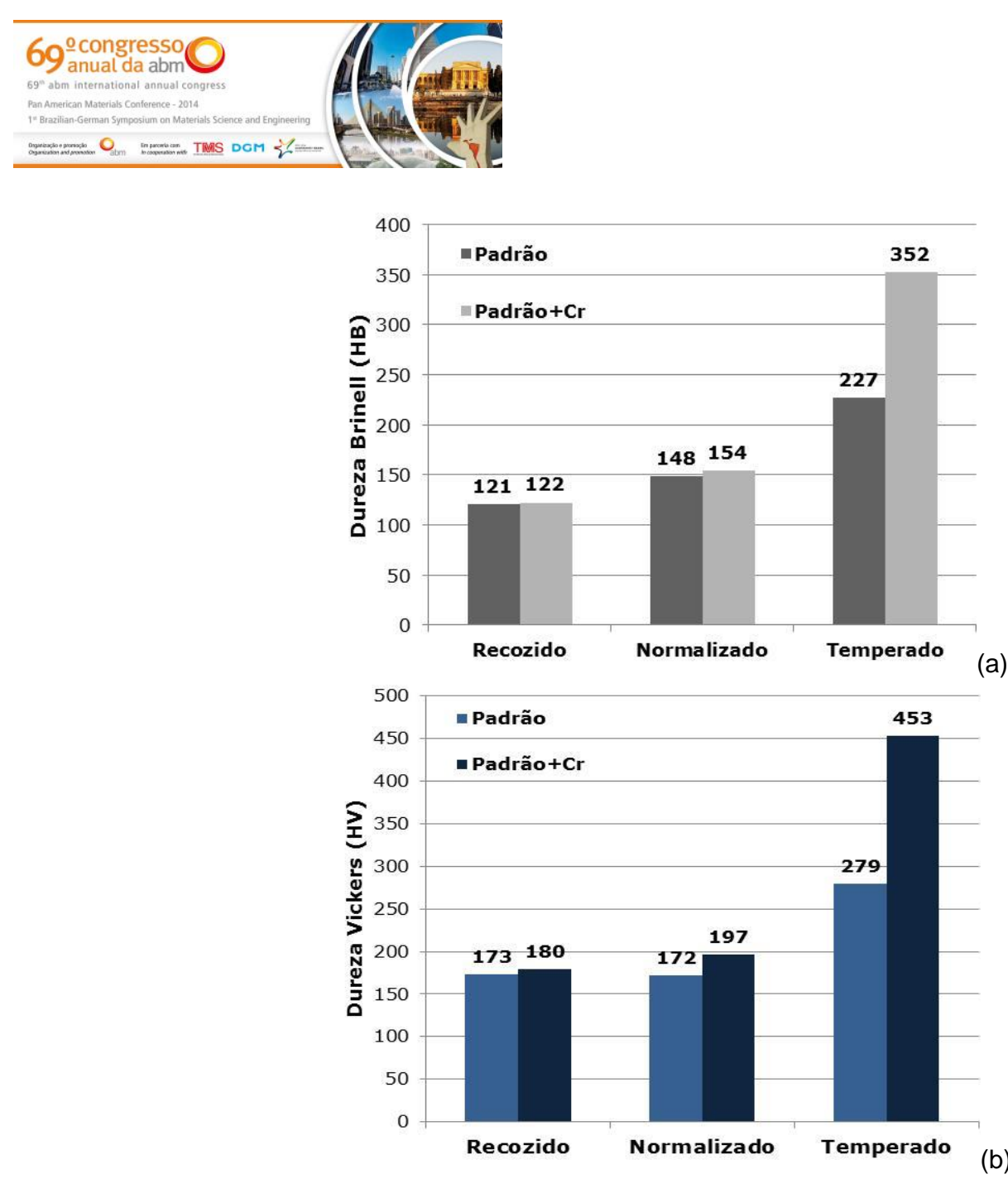

Figura 6. a) Valores de dureza brinell (HB) para as amostras recozidas, normalizadas e temperadas. b) Valores da microdureza vickers (HV) para as amostras recozidas, normalizadas e temperadas.

Nota-se a partir da figura 6 que os aços no estado normalizado têm maior microdureza do que no recozido, uma vez que na normalização a difusão de carbono para os interstícios é menor e como resultado forma-se uma estrutura muito mais refinada do que no recozimento. Comparando os resultados obtidos para os dois aços no estado normalizado, percebe-se que a microdureza do aço Padrão+Cr é um pouco maior do que no aço Padrão.

Como pode ser observado pelas micrografias (Figura 4), para os estado temperado, o aço Padrão+Cr apresentou uma quantidade de martensita muito maior do que o Padrão, e isso foi confirmado pela análise metalográfica e pela dureza $55 \%$ maior do aço Padrão+Cr em relação ao aço Padrão. Esse efeito já era esperado, pois o cromo desloca a curva do digrama TTT para à direita e isso leva a uma maior formação de mais martensita no aço Padrão+Cr do que no aço padrão mantida a mesma taxa de resfriamento.

O aumento da temperatura de revenimento acarretou a redução dos valores de dureza dos aços estudados (Figura 7). Este fato pode ser explicado pela difusão de carbono e subsequente formação e crescimento dos carbonetos. $O$ aumento do tamanho dos carbonetos diminui a área de contorno de grão por volume da cementita e facilitou o movimento das discordâncias. Como resultado houve a diminuição da dureza. A martensita perde carbono e torna a matriz menos dura através da difusão e com o aumento da temperatura o carbono combina-se com o ferro formado carbonetos que aumentam de tamanho, justificando a diminuição de dureza.

* Contribuição técnica ao 69 Congresso Anual da ABM - Internacional e ao 14ํㅡㄹ ENEMET - Encontro Nacional de Estudantes de Engenharia Metalúrgica, de Materiais e de Minas, 21 a 25 de julho de 2014, São Paulo, SP, Brasil. 


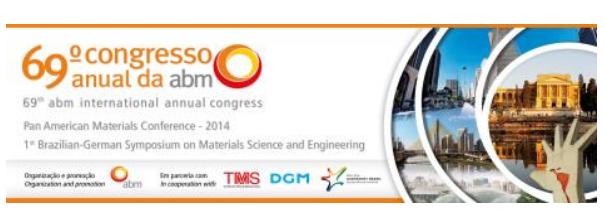

O aço Padrão+Cr possui durezas mais elevadas em todas as temperaturas de revenimento do que o aço Padrão (Figura 7). Este comportamento deve-se à maior temperabilidade e do decréscimo de dureza no revenimento proporcionadas pelo cromo.
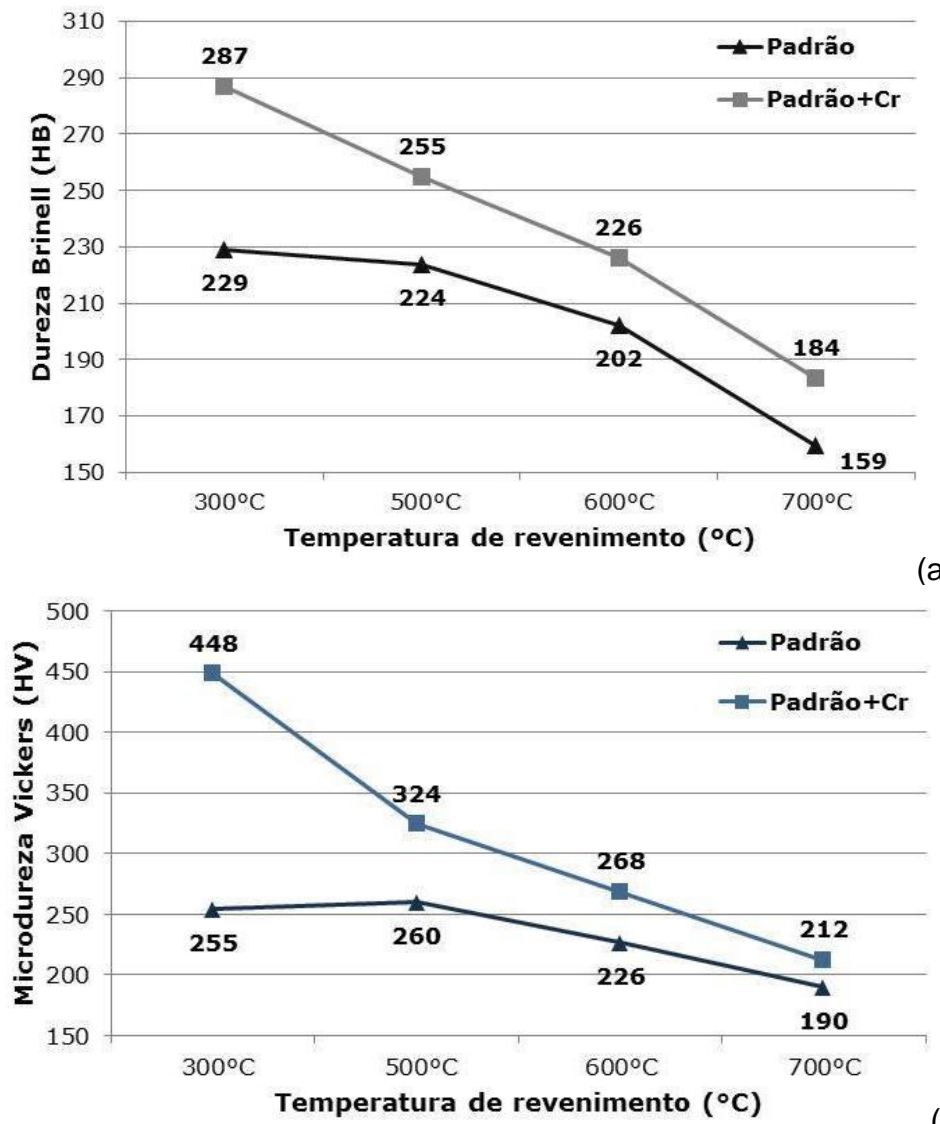

(a)

(b)

Figura 7. a) Curva de variação de dureza brinell (HB) em função da temperatura de revenimento para o aço Padrão e Padrão+Cr. b) Curva de variação de dureza vickers (HV) em função da temperatura de revenimento para o aço Padrão e Padrão+Cr.

\section{CONCLUSÃO}

A análise realizada dos resultados obtidos neste trabalho dá suporte às seguintes conclusões sobre a influência da adição de cromo nas propriedades dos aços estudados:

- A adição de cromo promove um aumento na dureza nos estados recozido e normalizado, consequentemente, melhora a resistência ao desgaste;

- O teor cromo presente nos aços estudados teve pouca influência no tamanho de grão austenítico;

- O cromo propiciou uma maior formação de martensita na têmpera e esse efeito foi confirmado pela análise metalográfica, dureza e microdureza;

- Como esperado o aumento da temperatura de revenimento provocou queda da dureza para o aço Padrão e Padrão+Cr, sendo que aço Padrão+Cr apresentou valores de dureza maiores do que o aço Padrão para as temperaturas de revenimento adotadas;

- Diferente para o aço Padrão+Cr onde se observou que a partir de $600^{\circ} \mathrm{C}$ iniciou a esferoidização, para o aço Padrão este processo ocorreu a $700^{\circ} \mathrm{C}$.

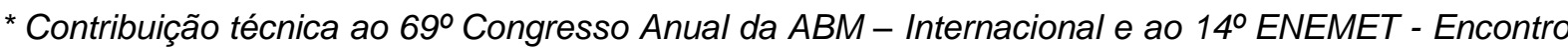
Nacional de Estudantes de Engenharia Metalúrgica, de Materiais e de Minas, 21 a 25 de julho de 2014, São Paulo, SP, Brasil.
} 


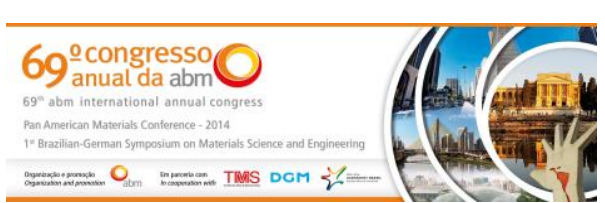

\section{REFERÊNCIAS}

1 Costa e Silva ALV, Mei PR. Aços e Ligas Especiais. São Paulo: Ed. Edgard Blücher; 2010.

2 Marchi LA. Variação da redução de área na estricção com o tempo, em condições isotérmicas em um aço médio-alto teor de carbono [dissertação de mestrado]. Belo Horizonte: Pós-Graduação em Engenharia Metalúrgica e de Minas, Universidade Federal de Minas Gerais; 2005.

3 Krauss G, Hudok D. Properties of Selection: Irons, steels, and High Performance Alloys. Ohio: ASM International; 1991.

4 Shkatov VV, Chernyshev AP, Lizunov VI. Kinetics of Pearlite Spheroidization in Carbon Steel. Author Affiliation: Lipetsk Polytechnical Institute. Physics Of Metals And Metallography (USSR) 70; 1990

5 Oliveira W. Influência do cromo no envelhecimento após deformação em fios de aço perlítico trefilados [dissertação de mestrado]. Belo Horizonte: Pós-Graduação em Engenharia Metalúrgica e de Minas, Universidade Federal de Minas Gerais; 2003.

6 Ridley N. Metallurgical Transactions. 1984;15A:1019-26.

7 Fagundes EJ. Análise da influência do ciclo de recozimento de esferoidização nas propriedades mecânicas do aço SAE 1050 [dissertação de mestrado]. Belo Horizonte: Pós-Graduação em Engenharia Metalúrgica e de Minas, Universidade Federal de Minas Gerais; 2006.

8 Chiaverini V. Aços e Ferros Fundidos: características gerais, tratamentos térmicos, principais tipos. São Paulo: Associação Brasileira de Metalurgia e Materiais; 2005.

9 Metals Handbook. Heating Treating, ASM International; 1991. v.4.

10 Callister JrWD. Ciência e Engenharia de Materiais uma Introdução. 5 $5^{\underline{a}}$ ed. Rio de Janeiro: LTC; 2002.

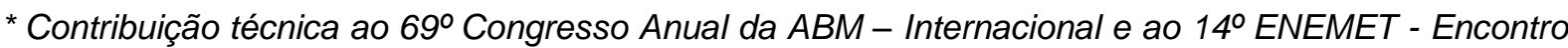
Nacional de Estudantes de Engenharia Metalúrgica, de Materiais e de Minas, 21 a 25 de julho de 2014, São Paulo, SP, Brasil. 